causes cooling in the North Atlantic and global surface warming to slow or stop will be a key point of debate.

The AMOC is deemed "very likely" to weaken in the coming decades ${ }^{1}$. Indeed, the Atlantic has seen muted rises in surface temperature relative to the global ocean over the past few decades. This relative lack of warming has been interpreted as a fingerprint of AMOC decline, potentially linked to anthropogenic climate change ${ }^{8}$. Whether the AMOC observatories will document the predicted decline remains to be seen, but they have already observed that the AMOC is in a weakened state ${ }^{9}$. Chen and Tung predict that such a weak AMOC will result in a period of rapid global surface warming that could last for more than two decades.

Gerard D. McCarthy and Peter W. Thorne are at the Irish Climate Analysis and Research Units (ICARUS), Department of Geography, Maynooth University, Maynooth, Ireland.

e-mails: gerard.mccarthy@mu.ie;

peter.thorne@mu.ie

1. Intergovernmental Panel on Climate Change (IPCC). Climate Change 2014: Synthesis Report. Contribution of Working Groups I, II and III to the Fifth Assessment Report of the Intergovernmental Panel on Climate Change (IPCC, 2014).

2. Chen, X. \& Tung, K.-K. Nature 559, 387-391 (2018).

3. Jackson, L. C. et al. Clim. Dyn. 45, 3299-3316 (2015).

4. Kosaka, Y. \& Xie, S.-P. Nature 501, 403-407 (2013).

5. Medhaug, I., Stolpe, M. B., Fischer, E. M., \& Knutti, R. Nature 545, 41-47 (2017)

6. Broecker, W. S. Oceanography 4, 79-89 (1991).

7. Drijfhout, S. Sci. Rep. 5, 14877 (2015).

8. Caesar, L., Rahmstorf, S., Robinson, A., Feulner, G. \& Saba, V. Nature 556, 191-196 (2018)

9. Smeed, D. A. et al. Geophys. Res. Lett. 45, 1527-1533 (2018).

\title{
Speciation far from the madding crowd
}

New species of marine fishes are found to emerge at a faster rate in high-latitude oceans, which have lower densities of species, than in the species-rich tropics. Are the tropics too crowded for new species to take hold? SEE LETTER P.392

\section{ARNE O. MOOERS \& DAN A. GREENBERG}

$\mathrm{T}$ he tropics are, like many cities, hot, busy and crowded. It was previously thought ${ }^{1}$ that these conditions in the tropics generate a hotbed for the formation of new species (speciation). Species diversity is remarkably high in the tropics and declines toward the poles. However, newly developed tools to measure speciation rates, coupled with ever-growing global data sets, have enabled the surprising finding that terrestrial speciation rates for the past few million years are similar across different latitudes ${ }^{2}$ or increase outside the tropics ${ }^{3}$. On page 392, Rabosky et al. ${ }^{4}$ document a speciation rate for marine fishes at high latitudes that is twice the speciation rate in tropical seas. This high speciation rate in cold, species-poor waters poses an interesting conundrum for evolutionary biologists and ecologists.

There are two potential drivers of high speciation rates in the tropics. First, the elevated temperatures in the region both speed up metabolism, increasing the number of mutations, and decrease generation times. This is a potentially powerful combination, producing more of the variation necessary for evolution and the possibility of faster evolution. A second possible driver is ecological opportunity. The energy-rich tropics offer abundant resources that can support many different niches. And the tropics are so rich in species that the interactions of members of a single species with its competitors, predators and parasites might differ from place to place, leading to different adaptations and eventual divergence into new niches ${ }^{1}$. Although this narrative makes for a compelling theory, Rabosky and colleagues' discovery suggests a different story, at least for marine fishes.

The authors gathered genetic data for 11,638 species of marine and freshwater fish, along with information on inferred evolutionary relationships based on taxonomic groupings for 19,888 additional fish species for which genetic data were not available. Using these data, and information from 139 dated fossil fishes, the authors generated a large set of plausible phylogenetic trees detailing the evolutionary relationships between all living marine fishes, and, crucially, estimates of when different lineages diverged from one another. These dated trees enable speciation rates to be inferred on the basis of the branching patterns of the tree. Species connected by short branches, and with many close relatives, have high speciation rates, whereas species that are separated by long branches and that have few close relatives have low speciation rates.

Most taxonomic groups are made up of lineages with both low and high speciation rates. The marine fishes in the authors' large phylogenetic trees were no exception, with

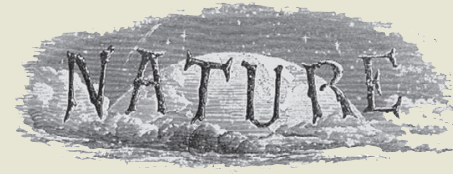

50 Years Ago

More than 7,000 people died in traffic accidents last year in Britain and nearly 94,000 were seriously injured ... The causes and possible preventative measures were the subject of a recent conference ... A police traffic superintendent is reported to have said that the defect which causes nearly every accident lies in "the nut holding the wheel". One contributor pointed out that road engineers should not assume that drivers are omniscient. "If asked to make more than one decision at a time, they will fail; if faced with a situation which can be misinterpreted, someone will eventually find the wrong meaning". The effect of human fallibility is easily apparent in the statistics ... during the last three months of 1967 ... after the breathalyser test came into operation ... driver and passenger casualties fell by 19 per cent, motor cyclist casualties by 16 per cent and pedal cyclists by 14 per cent. From Nature 20 July 1968

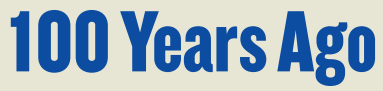

The utility of forests to a nation is one of the economic factors to its well-being which have been brought to an unforeseen prominence during the world-war: and perhaps to no other European nation has this ... development proved so startling, because so totally unsuspected, as to ourselves. Our woods were not grown from the commercial aspect - sport, amenity, and shelter to crops and stock were their main raison dêtre. We did not consider it necessary to grow woods for purely commercial reasons - that is, for the sake of the timber and pit wood and paper pulp, etc ... We obtained our requirements in these commodities by importing them from abroad, and relied on the Navy being able to safeguard these imports. We have now discovered our mistake and are paying for it. From Nature 18 July 1918 